Изучение интегральной и лоћальной чувствительности бопоюатоодов ...

\title{
A STUDY OF THE INTEGRAL AND LOCAL SENSITIVITY OF PHOTOCATHODES AND ITS INFLUENCE ON THE SCINTILLATION DETECTOR PLATEAU
}

(Abstract of preceding paper)

Joser S̆ILAR, OLGa Nováková

Research Institute for Electrotechnical Physics, Prague

In the framework of $\gamma$-ray spectroscopy a study was made of the integral, blue, and local sənsitivities of photocathodes from photomultipliers FEU 19, RCA 5819, EMU 5311 and Czechoslovak sample 61 PK 411, and their influence on the length and ascent of the scintillation detector plateau.

a) Integral sənsitivity of photocathodes. The integral sensitivity of photocathodes was measured in the standard way by means of a tungsten lamp with a colour temperature of $2870^{\circ} \mathrm{K}$. The current was measured in the circuit of the first dynode, which was galvanically connested with the following two dynodes. For an approximate estimation of the quality of the focussing system we measured the current in the first dynode as a function of the illumination of the photocathode (Fig. 1).

b) Blue sensitivity of photocathodes. The currently used luminescence substances have emission spectra that lie in the ultraviolet and blue range of wavelengths. For pulse measurements the blue sensitivity of photocathodes is therefore decisive. In our measurements we used the Jena BG 12 filter for determining the blue sensitivity. A relative comparison of the integral and blue sensitivities was carried out with an accuracy of $1 \%$ for RCA 5819 photomultipliers and with an accuracy of $2 \%$ for FEU 19 photomultipliers (Tab. 1). By comparing the blue and integral sensitivities we found that cathodes with the same integral sensitivity have different blue sensitivities (Fig. 2).

c) Local sensitivity. The inhomogeneity of the photocathode increases the statistical fluctuation of the pulse height of the scintillation detector. The distribution of sensitivity on the photocathode area of most photomultipliers is considerably inhomogeneous (Figs. 3 and 4). When determining the local sensitivity the photocathode was illuminated by a source of wavelength $4500(4100,3800) \AA$, and the current was measured on the output of the photomultioliers. It was found that the distribution of the local sensitivity on the photocathode area did not depend on the wavelength of the light used. With the photomultipliers FEU 19 we found a change in the photocathode sensitivity distribution with time. In the time interval considered (3 months) the RCA 5819 photomultipliers showed no essential change in the sensitivity distribution.

d) Scintillation detector plateau. For the plateau measurements we used an integral analyzer - made in our Institute. From the large number of our measurements dealing with the influence of the sensitivities of integral, blue (Fig. 6), and local (Fig. 5) photomultipliers on the length and slope of the plateau it follows that blue sensitivity influences the plateau length. The slope of the scintillation detector plateau depends both on the homogeneity and on the blue sensitivity of the photocathode.

Received 27.4. 1957.

\section{Iumepamypa - References}

[1] Engstrom R. W., Stoudenheimer R., Glover A. M.: Nucleonics, 10, (1952) 4, 58.

[2] Šilar J.: Jad. energie, 3 (1957) 1, 25. (На чепाском языке).

[3] Godlove T. F., Wadey W. G.: Rev. Sci. Instr., 25, (1954) 1, 1.

[4] Naray Z. S.: Acta fys. Acad. Sci. Hung., 4, (1955) 3, 253.

[5] Немилов Я. А., Обчинников В. М., Писаревсиий А. М.: Атом. әнергия, (1956) No 4, 51 .

[6] Morton G. A.: Adv. in Electr. IV (1952), 69.

[7] Чечик Н. О., Файнштейн С. II., Лифииц Т. М.: „әлектронные умножители“, Москва 1954.

[8] Šilar J.: Jad. energie 3 (1957), 7, 211. (На уешском языке). 